\title{
(1) \\ Association between Gastrointestinal Functional Disorders and Migraine Headache: A Therapeutic Link \\ CrossMark
}

\author{
Iraj Derakhshan ${ }^{1, *}$
}

\author{
Please cite this paper as: \\ Derakhshan I. Letter to the Editor : Association between Gastrointestinal Functional Disorders \\ and Migraine Headache: A Therapeutic Link. Midde East J Dig Dis 2018;10:121-122. \\ doi: $10.15171 /$ mejdd.2018.102.
}

\section{Dear Editor:}

As a neurologist with interest in pain control, ${ }^{1-2}$ I read the recent contribution by Lankarani and colleagues, ${ }^{3}$ on the relationship between gastrointestinal functional disorders and migraine, with great interest. I have the following comments concerning the therapeutic relationship between the said entities as follows. Although the respected authors did mention certain aspects of the therapeutic relationship between the two conditions, they did not sufficiently emphasize that connection. As pointed out in my recent article, ${ }^{2}$ patients suffering from migralepsy (migraine related epilepsy) were simultaneously relieved from both conditions if the headache were fully controlled (using daily scheduled opioids). Similarly, many of such patients with chronic daily headaches voluntarily stated that their gastrointestinal symptoms, of which they had suffered for years, had completely receded with the use of the abovementioned regimen. However, if the headache returned for any reason (most often because of running out of daily scheduled medication) the other condition (i.e. seizures or the gastrointestinal symptoms) returned as well. These comorbidities, therefore, speak of an identical or shared pathophysiology in these common conditions.

\section{ETHICAL APPROVAL}

There is nothing to be declared.

\section{CONFLICT OF INTEREST}

The authors declare no conflict of interest related to this work.

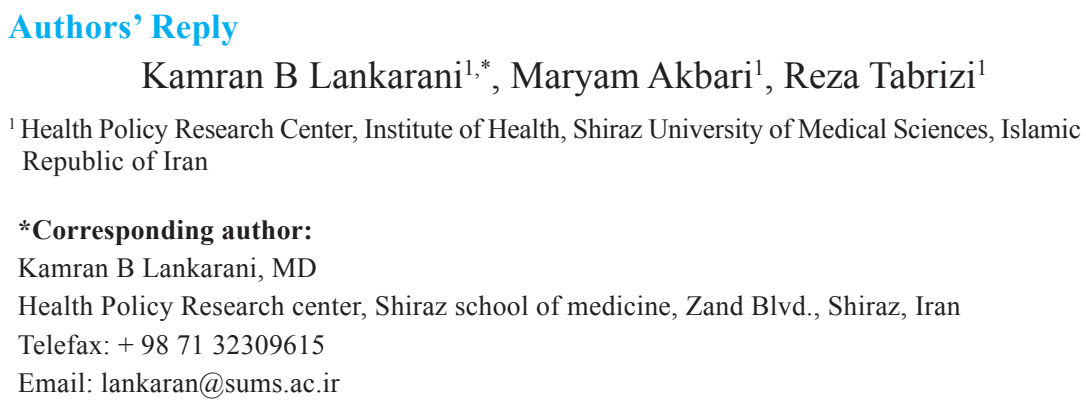

* Corresponding Author:
Iraj Derakhshan, MD
205 Cyrus Point, Charleston, WV 25314
Telefax: + 3043455174
Email: idneuro@hotmail.com
Received: 28 Nov. 2017
Accepted: 15 Jan. 2018


We appreciate the comments of Derakhshan on our population based research on the association between gastrointestinal functional disorders and migraine headache. ${ }^{4}$ He emphasized the possible therapeutic benefit of knowing this linkage and reported the beneficial effect of treating headache in gastrointestinal disorders mentioned by his patients in his daily practice. He also referred to his own work on treating five cases of migralepsy with opioids confessing treating the pain of headache resulted in disappearance of refractory seizures in those patients. ${ }^{5}$ None of the patients in his series were reported to have gastrointestinal symptoms.

Our study as we mentioned was a population based study exploring the detection of the linkage and was not aimed for therapeutic purposes. Several therapeutic trials on this issue were done previously but there is still a need for better designed studies with safer and more effective drugs. We have published an article before on the use of traditional Iranian remedies improving both functional gastrointestinal disorders and neurological symptoms. ${ }^{6}$ We think such trials would be very helpful as we have both conditions in common. These trials either could be targeting the headache with specific therapies and exploring the amelioration of gastrointestinal symptoms or vice versa. For the first methodology using maintenance drugs for migraine treatments such as sodium valproate could be considered. But starting with opioids could be criticized ethically considering their high potency for dependency and many side effects including worsening of constipation, nausea, and possible oncogenicity. ${ }^{7-9}$ For instance oxycodone that was reported by Derakhshan to control both headache and epilepsy had side effects of nausea in $31.1 \%$, vomiting in $14.8 \%$, and constipation in $53.1 \%$ of adult patients using the drug. ${ }^{10}$

It should be also emphasized that migralepsy is a quite rare manifestation of migraine, which we did not find even a single such case in our studied population.

In conclusion while considering the necessity for therapeutic trials in patients suffering from both migraine headache and functional gastrointestinal disorders with the use of safe drugs, any such studies need to be well designed to avoid the placebo effect and to look for long term results specially considering the quality of life.

\section{REFERENCES}

1. Derakhshan I. Regarding the Significance of Non-Phase Locked Oscillatory Brain Activity in Response to Noxious Stimuli. Can J Neurol Sci 2016;43:609-10.

2. Derakhshan I. Killing two birds with one stone: successful opioid monotherapy in intractable migraine-triggered epilepsy, a case series. Ther Adv Chronic Dis 2017;8:1215. doi: $10.1177 / 2040622316683162$

3. Lankarani KB, Akbari M, Tabrizi R. Association of Gastrointestinal Functional Disorders and Migraine Headache: a Population Base Study. Middle East J Dig Dis 2017;9:139-145. doi: 10.15171/mejdd.2017.64.

4. Lankarani KB, Akbari M, Tabrizi R. Association of Gastrointestinal Functional Disorders and Migraine Headache: a Population Base Study. Middle East J Dig Dis 2017;9:139-45. doi: 10.15171/mejdd.2017.64.

5. Derakhshan I. Killing two birds with one stone: successful opioid monotherapy in intractable migraine-triggered epilepsy, a case series. Ther Adv Chronic Dis 2017;8:1215. doi: $10.1177 / 2040622316683162$

6. Pasalar M, Choopani R, Rezaeizadeh H, Ranjbar M, Lankarani KB. A traditional Persian medicine beverage could improve quality of life in dyspeptic patients. Planta Med 2016;82.

7. Lankarani KB. Opium, an oncogene or a marker of oncogenic behaviors? Am J Gastroenterol 2014;109:600. doi: 10.1038/ajg.2014.15.

8. Sadjadi A, Derakhshan MH, Yazdanbod A, Boreiri M, Parsaeian M, Babaei M, et al. Neglected role of hookah and opium in gastric carcinogenesis: a cohort study on risk factors and attributable fractions. Int $J$ Cancer 2014;134:181-8. doi: 10.1002/ijc.28344.

9. Carter GT, Duong V, Ho S, Ngo KC, Greer CL, Weeks DL. Side effects of commonly prescribed analgesic medications. Phys Med Rehabil Clin N Am 2014;25:457-70. doi: 10.1016/j.pmr.2014.01.007.

10. Anastassopoulos KP, Chow W, Ackerman SJ, Tapia C, Benson C, Kim MS. Oxycodone-related side effects: impact on degree of bother, adherence, pain relief, satisfaction, and quality of life. J Opioid Manag 2011;7:203-15. 